\title{
Characterization of the seismic dynamical state through joint analysis of earthquakes and seismic noise: the example of Ischia Volcanic Island (Italy)
}

\author{
Paola Cusano $^{1}$, Simona Petrosino ${ }^{1}$, Enza De Lauro ${ }^{2}$, Salvatore De Martino ${ }^{2}$, and Mariarosaria Falanga ${ }^{2}$ \\ ${ }^{1}$ Istituto Nazionale di Geofisica e Vulcanologia, Sezione di Napoli - Osservatorio Vesuviano, Naples, Italy \\ ${ }^{2}$ Dipartimento di Ingegneria dell'Informazione ed Elettrica e Matematica applicata/DIEM, \\ Università degli Studi di Salerno, Fisciano, Italy
}

Correspondence: Mariarosaria Falanga (mfalanga@unisa.it)

Received: 12 December 2019 - Revised: 15 March 2020 - Accepted: 2 April 2020 - Published: 9 April 2020

\begin{abstract}
This work is devoted to the study of both earthquakes and background seismic noise at Ischia Island (Italy) recorded pre and post the $M_{\mathrm{d}} 4.0$ earthquake occurred on 21 August 2017 (18:57 UTC). We compare and characterize noise and earthquakes in terms of Independent Component Analysis, energy and polarization properties. The earthquakes' waveforms and the background noise are decomposed into a few independent components with two main common signals peaked around $1-2$ and $3-4 \mathrm{~Hz}$, respectively. A slight increase of the energy of the background seismic noise is observed comparing samples recorded in 2016 and 2017, whereas no variations are detected in 2017 pre and post the main earthquake. The polarization analysis, performed in the frequency bands individuated by Independent Component Analysis and applied to the background seismic noise, indicates a shallow propagation and the azimuthal pattern is mainly controlled by the local structural features. These results suggest that noise and earthquakes are ascribable to a common phenomenon of fluid-solid interaction in the hydrothermal system of Ischia Island.
\end{abstract}

\section{Introduction}

The interaction between fluid flow and solid rock of the shallow plumbing system of a volcano is one of the most common mechanisms that drives the dynamics of the volcanic areas. In particular, the coupling between a fluid phase (e.g., magma-gas flow or hydrothermal flux) and the vibrations of the solid matrix (e.g., the volcano edifice) generates those seismic signals typically observed on volcanoes (e.g. low frequency and hybrid events, volcanic tremor; see McNutt, 2005 , and references therein) and, at larger time scale, it may induce synchronization mechanisms between seismic signals and solid earth tides (De Lauro et al., 2012, 2013, 2018; Falanga et al., 2019). Starting from the seminal work of Aki et al. (1977) who proposed a fluid-filled crack as resonating source of the volcanic tremor observed at Kilauea, several physical models based on the fluid-rock interaction have been proposed to interpret the seismic signals in volcanic areas (see, e.g., Chouet and Matoza, 2013, and references therein). In many cases, the same physical mechanism can generate a variety of signals (long period events and volcanic tremor), depending on the boundary conditions (Kawakatsu and Yamamoto, 2007). In this framework, the fluid pressure in the plumbing system is one of the key point in determining the behavior of a volcano. Indeed, depending on the pressurization state, common source processes can generate different styles of activity, from continuous and sustained low-energy tremor up to higher magnitude seismic events (Chouet and Matoza, 2013; Fazio et al., 2017). This interplay between pressure-induced changes in the fluid circulations and variations of the seismic background patterns, thus represents one of the most useful observables in tracking the evolution of volcanic systems (Madonia et al., 2008; Chiodini et al., 2017; Petrosino et al., 2018, 2020). In particular, in hydrothermal environments, the fluid-rock interaction assumes a crucial role in controlling the overall dynamics.

The volcanic island of Ischia, which belongs to the Phlegrean Volcanic District, Southern Italy, represents an ideal 

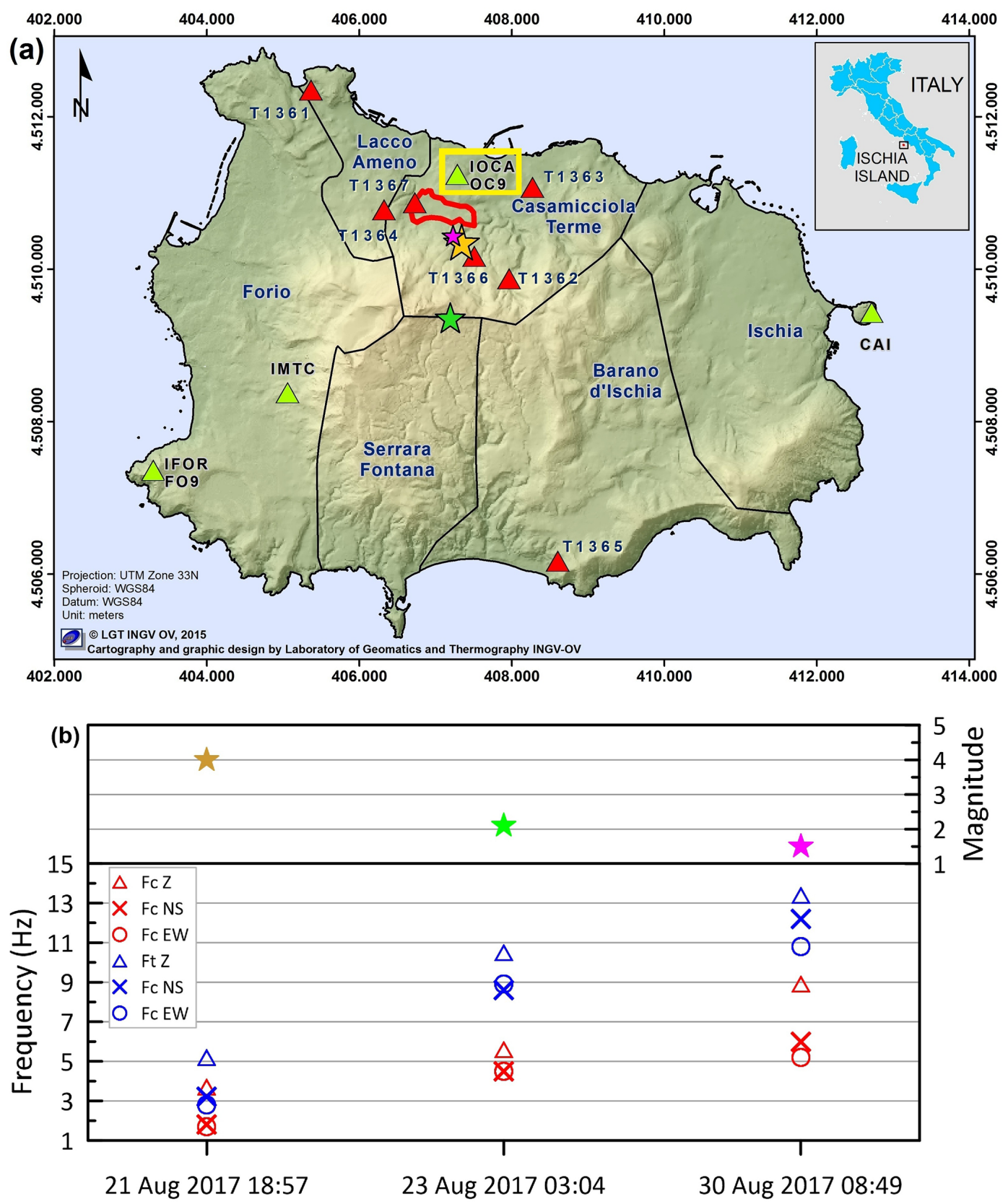

Figure 1. (a) Map of Ischia Island. Permanent (green triangles) and Mobile (red triangles) Seismic Networks (for technical details see Moretti et al., 2016; D'Auria et al., 2018; Galluzzo et al., 2019). The yellow box indicates the reference station, IOCA, used for the present analyses. The location of the IE17 and of the two major aftershocks is marked by a golden, a green and a magenta star, respectively, whose dimension is proportional to magnitude. The red line delimits the area most struck by the IE17; (b) Values of corner frequency $\left(F_{\mathrm{c}}\right)$ and frequency threshold $\left(F_{\mathrm{t}}\right)$ below which the $95 \%$ of the cumulative energy is released, obtained from the spectral analysis of the three earthquakes recorded at the three-component IOCA station. The duration magnitude $M_{\mathrm{d}}$ is reported in the upper part of panel (b).

candidate for studying the effects related to liquid-solid coupling phenomena. The geological history of Ischia has been described in many papers (see e.g. de Vita et al., 2010, and references therein); the island is subjected to a slow subsidence, whereas the central portion of the caldera is characterized by the resurgent block, the Mt. Epomeo, possibly originated by a magmatic intrusion (Orsi et al., 1991). As a result of a complex interaction among ground deformation, volcano-tectonic dynamics and underground fluid circulations, Ischia hosts a geothermal system whose surface manifestations consist in both fumaroles' activity and thermal springs (Di Napoli et al., 2009, 2013; Carlino et al., 2014; Di 

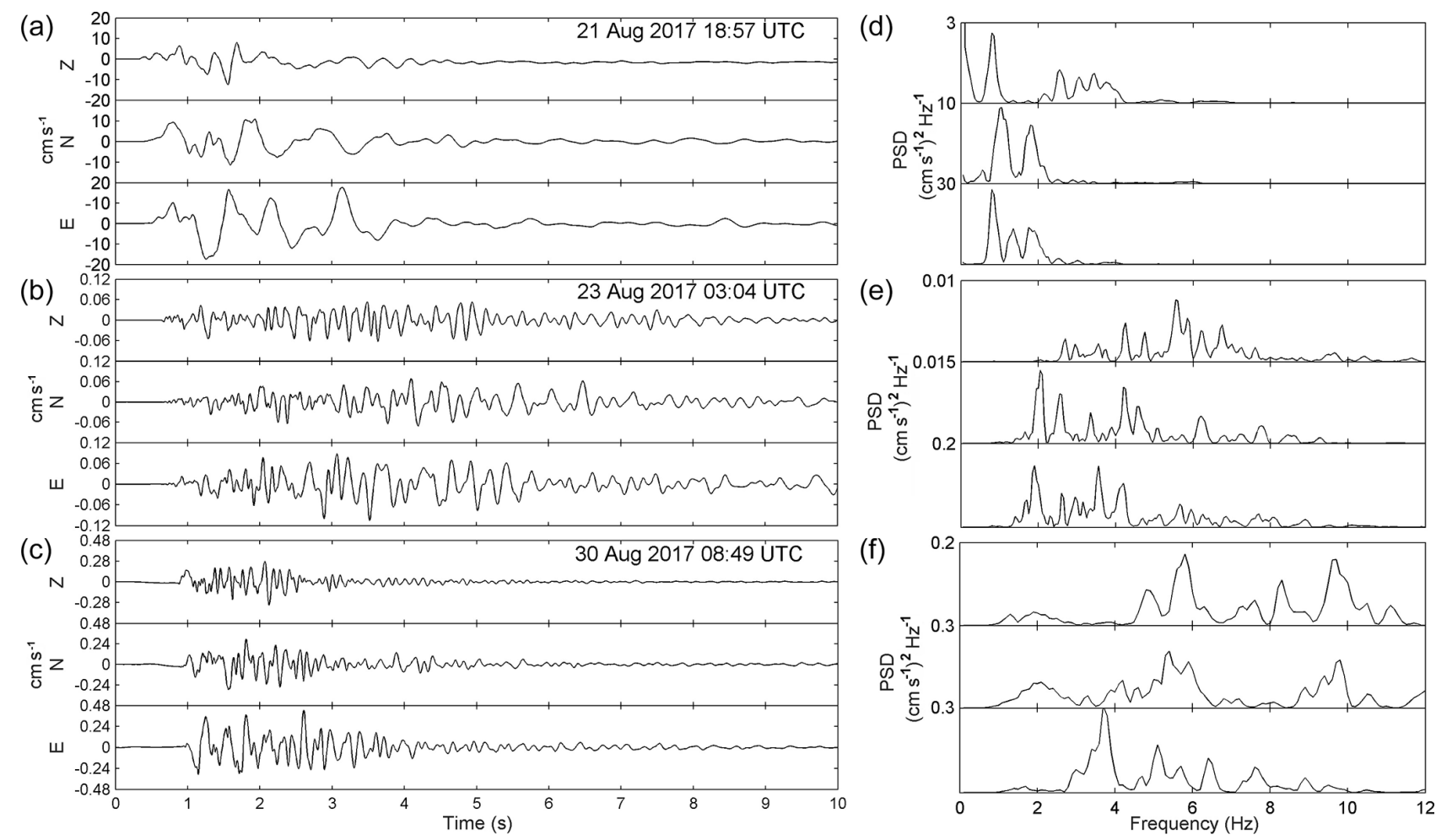

Figure 2. Ischia earthquakes recorded by the three-component ( $Z, \mathrm{~N}$ and E) IOCA accelerometer (integrated traces). In panels (a)-(c) the earthquake signals are reported with the indication of the date and time; in panels (d)-(f), the corresponding Power Spectral Densities.

Giuseppe et al., 2017; Piochi et al., 2019). The geothermal fluids are a mixing of meteoric, sea water, as well as thermal fluids rising from distinct superimposed reservoirs at depths ranging from 150 up to $1000 \mathrm{~m}$ b.s.l. (Di Napoli et al., 2009, 2013). The hydrothermal fluid circulation is constrained by the stratification of different volcanic deposits and the fluid flow occurs along pathways of high permeability, such as fractures and faults (Carlino et al., 2014).

The northern part of the resurgent block, between Casamicciola and Lacco Ameno, is marked by E-W and SW-NE faults and corresponds to the main source area of the historical seismicity (Rovida et al., 2019). In the last years, the seismic activity has been low, but on 21 August 2017 (18:57 UTC) a $M_{\mathrm{d}} 4.0\left(M_{\mathrm{w}} 3.9\right)$ earthquake struck the northern sector of the island, causing two fatalities and many damages in the Casamicciola area. The earthquake (hereinafter referred to IE17) triggered a significant ground displacement (Devoti et al., 2018) and tilting (Ricco et al., 2019) and it was followed by a sequence of about 20 aftershocks (Nappi et al., 2018) located at shallow depths $(<2.5 \mathrm{~km}$ b.s.l.). The interpretation of the source process of the IE17 is still controversial: re-activation caused by tectonic stress of an EW striking fault with south (De Novellis et al., 2018) or north (Nappi et al., 2018) dipping, or complex rupture involving a normal faulting event triggering a shallow underground collapse (Braun et al., 2018), are some of the possi- ble generation mechanisms that have been proposed. Interestingly, Calderoni et al. (2019) have highlighted the significant role of the hydrothermal fluids in triggering seismicity through the pressurization/depressurization cycles of the hydrothermal reservoir. The role of the hydrothermal system in the generation of the background seismic signal has been furtherly investigated by Cusano et al. (2020). The authors found evidences of a persistent source producing a background seismic signal with well-defined spectral frequencies, which can be modelled as a whisper on the basis of the theory of voiced and unvoiced phonation.

In the present work, we investigate the dynamical state of Ischia island through joint analysis of earthquakes and seismic noise. As in Cusano et al. (2020), we use a multiparametric approach based on the high-order statistical analysis, energy release and polarization estimates, for the identification of the main features of the signals. Standard and innovative techniques, spanning from FFT to Independent Component Analysis (ICA; Ciaramella et al., 2006; Bottiglieri et al., 2007; Capuano et al., 2016), have been applied in frequency and time domain to the seismic data. Moreover, handling a continuous signal such as seismic noise, we derive the average properties of the wavefield on hourly scales (Capuano et al., 2017) and their eventual temporal variation before and after the IE17. Finally, we propose a conceptual model to interpret the generation mechanism of both earth- 
(a)

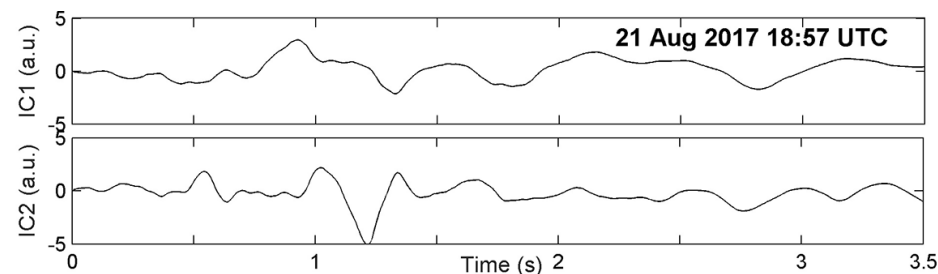

(b)

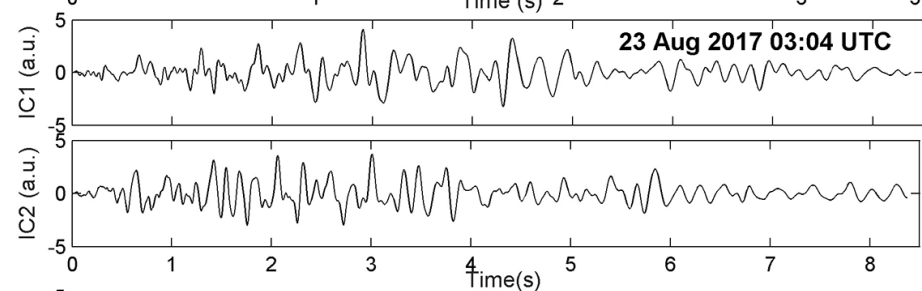

(c)

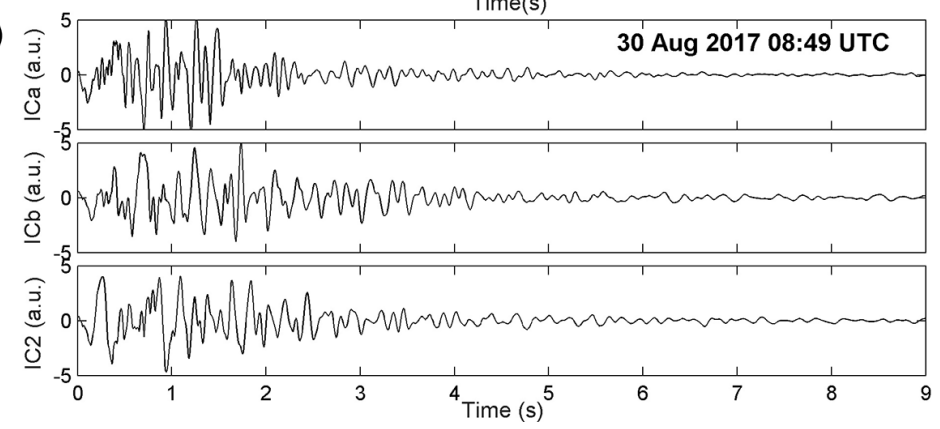

(d)

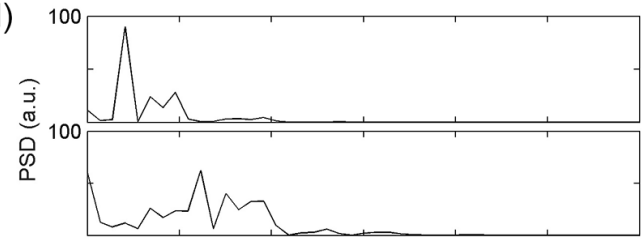

(e)

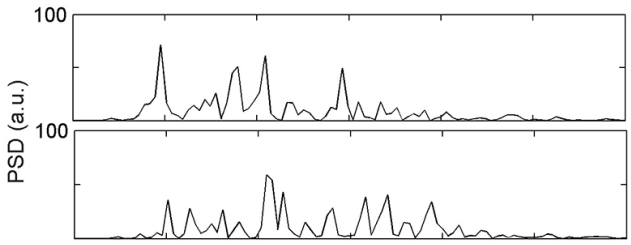

(f)

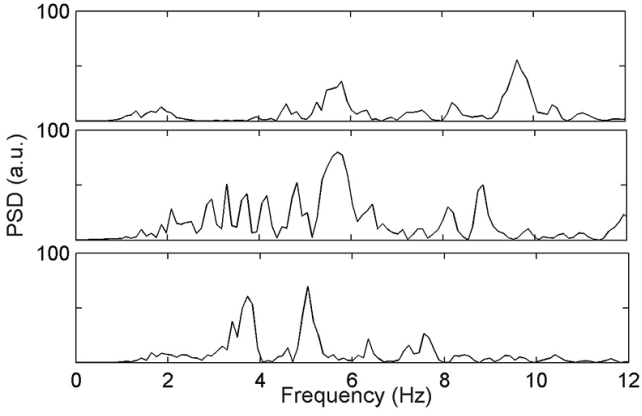

Figure 3. ICA results for Ischia earthquakes: in panels (a), (b), (c), the ICs are reported with the indication of the date and time; in panels (d), (e), (f), the corresponding Power Spectral Densities.

quakes and seismic noise in a unique framework. For our study, we used the signals recorded by the digital broadband seismic station IOCA (Fig. 1a), equipped with a velocimeter and an accelerometer, which belongs to the Permanent Seismic Network (PSN) managed by Istituto Nazionale di Geofisica e Vulcanologia - Osservatorio Vesuviano.

\section{Spectral and independent component analysis of earthquakes}

We analysed the main earthquake IE17 and the two major aftershocks (dates and times reported Fig. 1b). Since the waveforms of IE17 saturated on several velocimeter devices, we used the signals recorded by the accelerometric sensors of IOCA station and integrated them to derive velocity time series. The waveforms and spectra (PSD) are shown in Fig. 2: the latter are indicative of the frequency bands mainly involved in the energy release process. In particular, for the three directions of ground motion (vertical $Z$, NS and EW) we calculated the corner frequency $\left(F_{\mathrm{c}}\right)$ and the frequency threshold $\left(F_{\mathrm{t}}\right)$ below which the $95 \%$ of the cumulative energy is released (Fig. 1b). For all the three events, we have the most energy emitted below $12 \mathrm{~Hz}$.

The further analysis is aimed to decompose the waveforms into independent components (ICs) which represent the "basic" signals related to the source. To achieve that goal, we applied ICA (Hyvärinen et al., 2001), a technique that led to innovative results in several scientific fields (e.g., Bottiglieri et al., 2007; Palo and Cusano, 2013; De Lauro et al., 2016, 2018). It operates in time-domain and it is able to find underlying sources from multivariate statistical data on the basis of their statistical independence, evaluated by using fourthorder statistics.

Earthquakes can be considered as a particular linear mixture of some undetermined independent signals associated even to different sources. Thus, following the methodological approach proposed by De Lauro et al. (2016), we applied ICA to the three directions of motion of each event recorded at IOCA station. Figure 3 contains the time series extracted by ICA and the relative spectra (PSD). The lengths of the time windows take into account the whole information on the dynamics of the phenomena, and, hence, essentially depend on the energy of the earthquakes. The separated signals (ICs) show distinctive spectral content. In particular, the earthquakes occurred on 21 and 23 August are both characterized by the extraction of only two independent sources with spectra peaked at $1-2 \mathrm{~Hz}$ (IC1) and $3-4 \mathrm{~Hz}$ (IC2), respectively. These ICs share the same typical frequency content of the background seismic signals associated to the geothermal activity (Cusano et al., 2020), likely indicating an underlying common source mechanism for both earthquakes and hydrothermal oscillations. A different behaviour is shown by the earthquake occurred on 30 August: the number of ICs is 
(a)

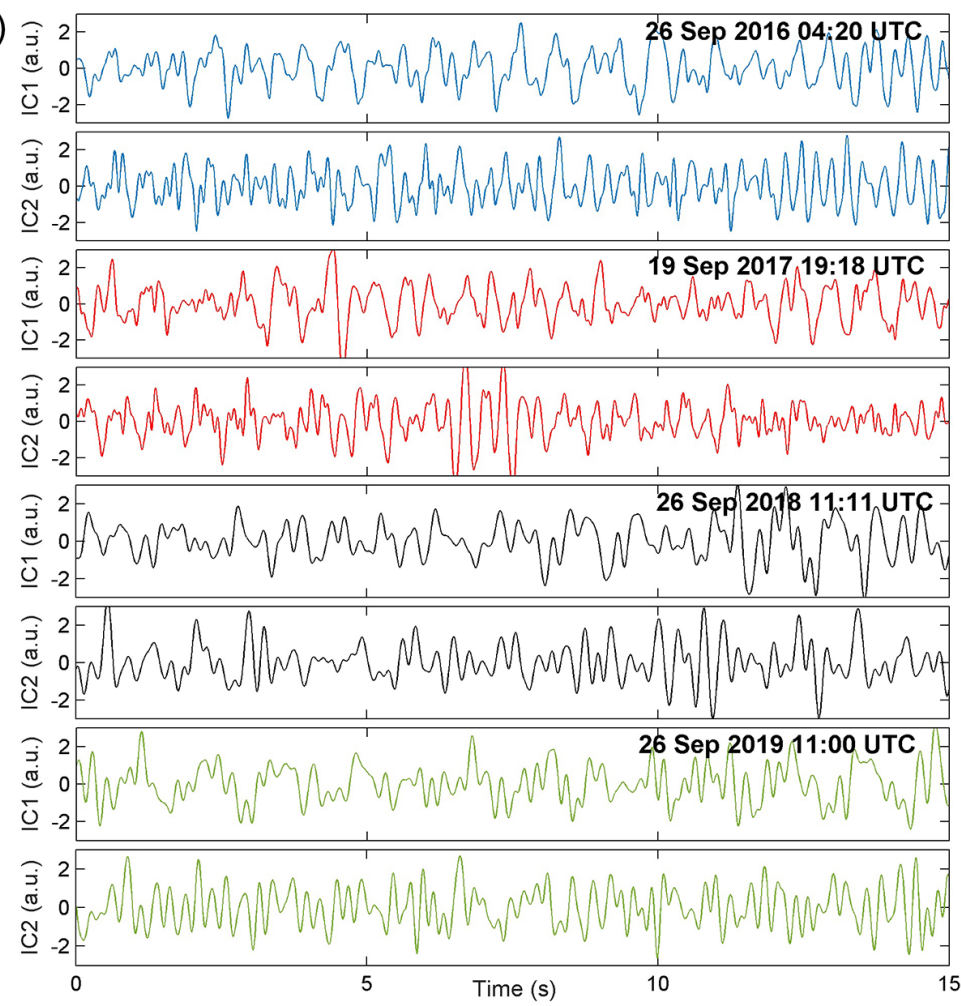

(b)

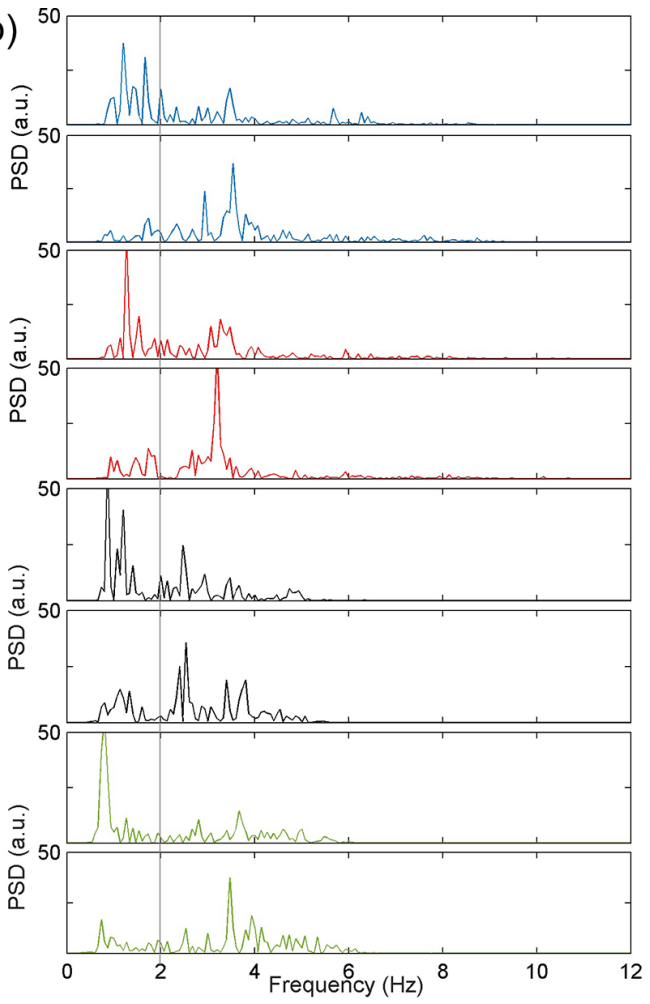

Figure 4. Examples of the ICA results relative to the seismic noise for IOCA station. The plots for the year 2016 are represented in blue, 2017 in red, 2018 in black and 2019 in green. In panel (a), we report the ICs' signals (IC1 and IC2); in panel (b), the corresponding estimated PSDs. The starting time of the used time-windows are indicated. The grey vertical line on the PSD plots evidences that the two ICs are well separated in the frequency domain.

increased to three and their spectra are shifted towards higher frequencies. Just the component labelled with IC2 is in common with the other two events, whereas the remaining ICs are very different, with a frequency content peaked around $10 \mathrm{~Hz}$ (ICa) and 5-6 Hz (ICb). We hypothesize that this event may have occurred as a superposition of components ( $\mathrm{ICb}$ and ICa), ascribable to rock fractures, on a pre-existing oscillation (IC2) of hydrothermal nature (also present in the background noise), thus suggesting a more similar to tectonic than hydrothermal source mechanism.

\section{Seismic Noise}

We analysed the seismic noise recorded in different years with the aim of characterizing its patterns and tracking eventual temporal variations before and after the IE17.

\subsection{Spectral and independent component analysis}

Results from a standard spectral analysis evidence that the major frequency content of the noise wavefield is below $6 \mathrm{~Hz}$; in particular, common frequency peaks in the 1-2 and 3$4 \mathrm{~Hz}$ bands are well detectable. By analysing the noise after the IE17, Cusano et al. (2020) evidenced the distribution of the energy over these two frequency bands and recognized the existence of two separated signals: IC1 results stable and persistent, IC2 shows amplitude modulation over the $24 \mathrm{~h}$. Going further, we checked the stability of the two ICs over the time by applying ICA to the noise before and after the IE17. We analysed 100 noise samples, randomly chosen, at IOCA station over the years 2016, 2017, 2018 and 2019, using $15 \mathrm{~s}$-long time-windows, filtered in $0.8-10 \mathrm{~Hz}$ band. The results (Fig. 4) confirm the stability over the time of the ICs' pattern found in Cusano et al. (2020):

1. IC1 is dominant, persistent and it is extracted all over the time-windows analysed, strongly indicating a link to a source which is steady and sustained;

2. The temporal behaviour of the spectral amplitude in the IC2 band shows an amplitude modulation over the $24 \mathrm{~h}$, which could be linked to anthropogenic factors.

\subsection{RMS amplitude and energy release}

We computed the Root Mean Square (RMS) of $1 \mathrm{~h}$-long samples continuously recorded by IOCA station during three months (August, September and October) in the years 2016 and 2017, respectively. Data were filtered in the 1-2 and 


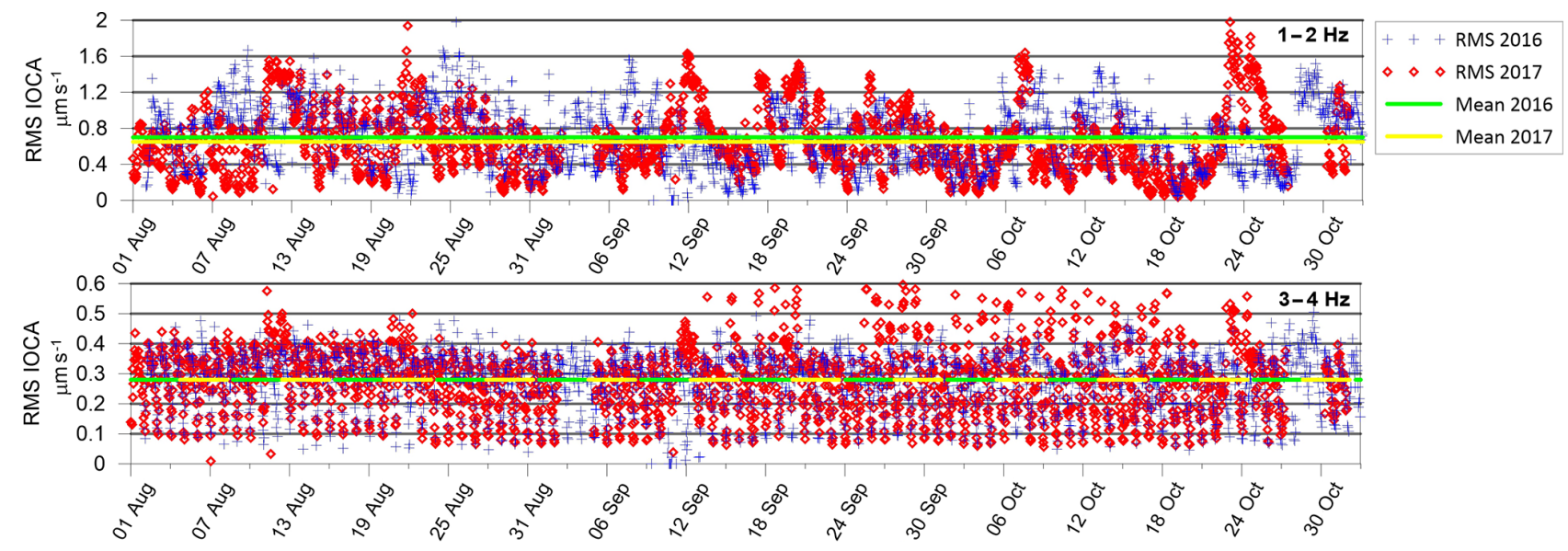

Figure 5. Time evolution of the RMS of the seismic noise recorded during the time interval August-October 2016 (blue) and 2017 (red), in the 1-2 and 3-4 Hz frequency bands. The mean value of the RMS is indicated by the green (2016) and yellow (2017) lines. Note that we used different scales for the $y$ axis, due to the different energy content in the two bands.

$3-4 \mathrm{~Hz}$ frequency ranges which correspond to the two ICs and the obtained values were averaged over the three directions of motion. The time evolution of the RMS amplitude is shown in Fig. 5; on the average, the results for the 2016 and 2017 datasets are comparable for the two analysed frequency bands.

Indeed, looking at the RMS amplitude distribution represented by the histograms in Fig. 6, the release of energy (which is proportional to the squared amplitude) in 2016 and 2017 occurs over the same ranges. The RMS amplitude appears more spread in the $1-2 \mathrm{~Hz}$ band. For the $3-4 \mathrm{~Hz}$ band the histograms are peaked on lower amplitude values. However, in 2017 for both the frequency bands, the distributions have a tail towards slightly higher values compared to the histograms relative to 2016 .

\subsection{Polarization properties}

We estimated the polarization parameters (Montalbetti and Kanasewich, 1970; De Lauro et al., 2016) of the same data set used for the RMS analysis. The continuous signal was filtered in the 1-2 and 3-4 Hz frequency bands and windowed by sliding time windows which contain 1.5 wave cycles of the maximum period. The azimuthal distribution is represented by the rose plots in Fig. 7. As it can be seen, the signal is polarized in the horizontal plane. No variations occurred during the analysed time intervals. In both the two frequency bands, the azimuths retain almost constant values in the range $120-140^{\circ}$ (roughly NW-SE orientation). The comparison between the two frequency bands shows that in the 1-2 $\mathrm{Hz}$ band the population is less disperse with respect to those in the $3-4 \mathrm{~Hz}$ band. In addition, the incidence angles in the range $70-90^{\circ}$ indicates a shallow propagation of the noise wavefield.
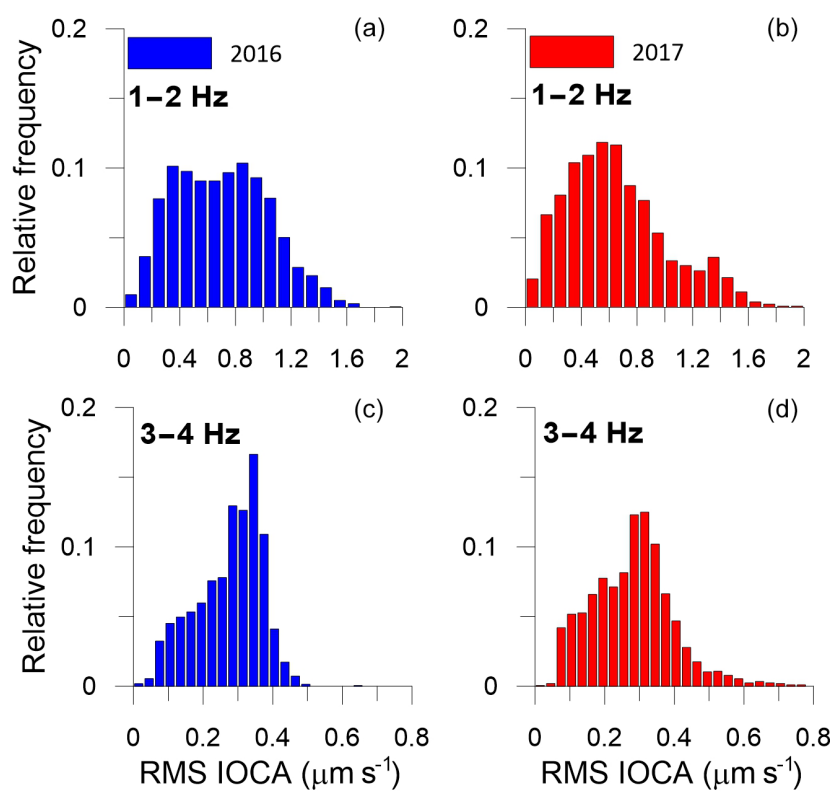

Figure 6. Amplitude distribution of the RMS of the seismic noise recorded during the time interval August-October 2016 (blue) and 2017 (red) in the $1-2 \mathrm{~Hz}(\mathbf{a}, \mathbf{b})$ and $3-4 \mathrm{~Hz}(\mathbf{c}, \mathbf{d})$ frequency bands.

\section{Discussion and conclusions}

We performed a detailed analysis of both earthquakes and background seismic noise at Ischia Island, characterizing them in terms of independent components, energy and polarization properties and comparing the patterns recovered pre and post the IE17. Moreover, we searched for common features between noise and earthquake signals.

Summarizing, the results presented in this work suggest: 

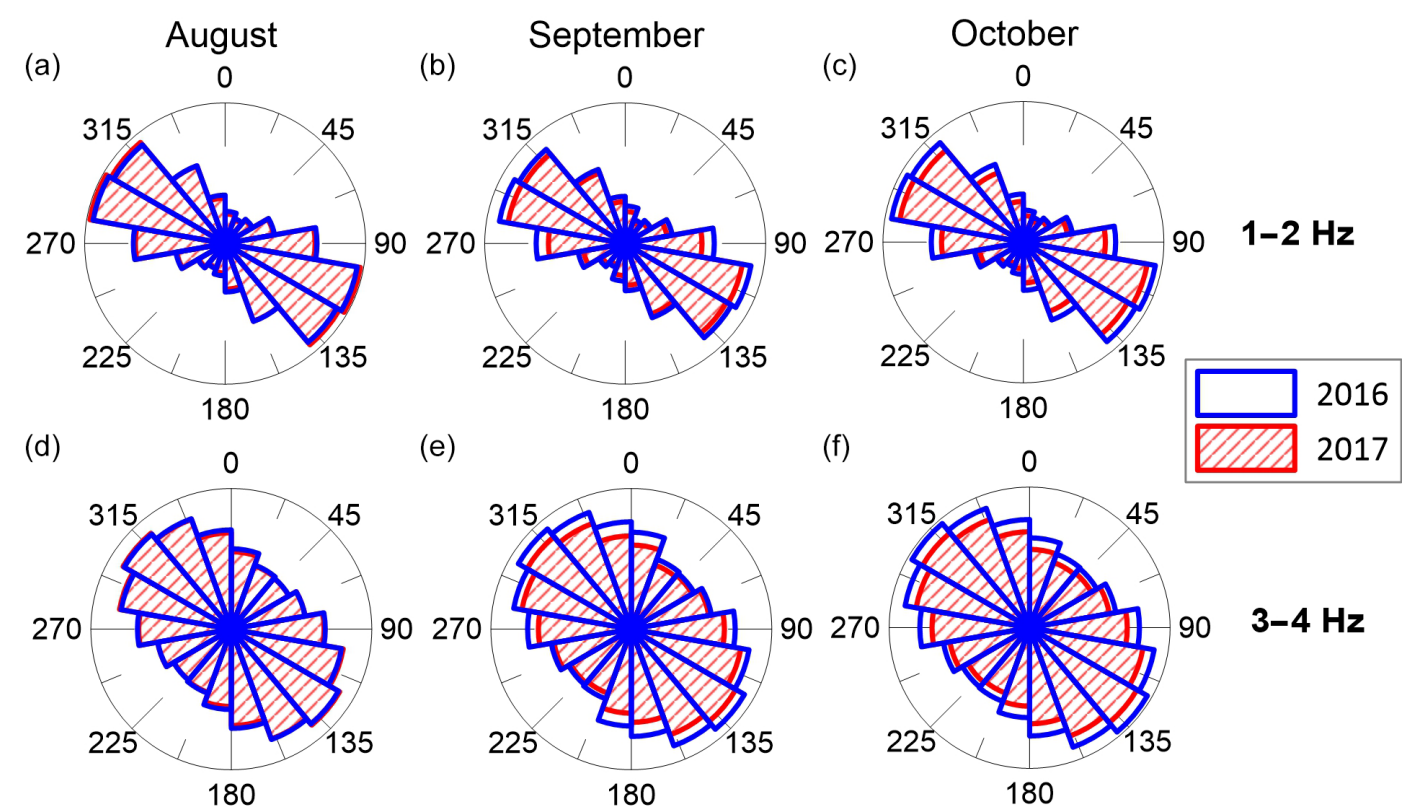

Figure 7. Monthly azimuthal distribution of the seismic noise in the time interval August-October 2016 (blue rose plot) and 2017 (red rose plot) obtained at IOCA station in the $1-2 \mathrm{~Hz}(\mathbf{a}-\mathbf{c})$ and $3-4 \mathrm{~Hz}(\mathbf{d}-\mathbf{f})$ frequency bands.

1. ICA decomposes the earthquake waveforms into two main and independent signals (time components), IC1 $(1-2 \mathrm{~Hz})$ and IC2 $(3-4 \mathrm{~Hz})$.

2. ICA decomposes the background noise into two main and independent signals (time components), IC1 (1$2 \mathrm{~Hz})$ and IC2 $(3-4 \mathrm{~Hz})$. IC1 is the most energetic. IC1 and IC2 are always extracted along the whole investigated time intervals (2016-2019).

3. A slight increase of the energy (in terms of RMS) of the background seismic noise is observed comparing 2016 and 2017. Instead, no variations in the RMS levels are detected in 2017, before and after the IE17.

4. The polarization analysis, performed in the frequency bands individuated by ICA, shows azimuth and incident angle values which are stable over the investigated time intervals. The incidence angles indicate a shallow propagation and the azimuthal pattern is mainly controlled by the structural features like faults and fractures $(\mathrm{Cu}-$ sano et al., 2020).

Considering the persistent behaviour of IC1 in the seismic noise, we can ascribe this component to a phenomenon of fluid-solid interaction in the hydrothermal system, which results in a continuous whisper of the shallow geothermal activity. In line with Cusano et al. (2020), considering that the solid structure of the surficial hydrothermal reservoir can be made by a network of conduits persistently prompted by the circulating fluids, it is likely to hypothesize that the system undergoes to oscillations. In the framework of an organ pipe like model, the band (1-2) $\mathrm{Hz}$ could be associated with the persistent activity of the shallow hydrothermal system and, reasonably, it could correspond to the fundamental mode of oscillation. Whether the pressure field in the fluid is sufficiently high, also the higher modes can be triggered, with a shift towards higher frequencies, due to non-linearity of the pipe. In this conceptual scheme, IC2 could represent the higher mode of an hydrothermal source (anyway modulated by anthropogenic noise), whose main signature is contained in IC1. Interestingly, a cyclic behaviour has also been observed in the temporal patterns of some geochemical indicators, likely due the pumping of the thermal water in the spas (Caliro et al., 1999; Di Napoli et al., 2009; Piochi et al., 2019). This action would in turn favor the mixing processes between shallow and deep fluids, reflecting how strict the link between the hydrothermal reservoir and anthropic activity related to the exploitation of the thermal resources on the island can be.

A relevant aspect is that ICA decomposes the IE17 into components that share the same frequency content of the noise. This yields to hypothesize a strong connection in terms of source between the earthquakes and the noise. Considering that the frequencies involved are the same, we can infer that both the signals are related to oscillations of the shallow hydrothermal system. Indeed, the basic structure oscillates with normal mode at $1-2 \mathrm{~Hz}$ and an abrupt increase (above a certain threshold) of the fluid pressure may have triggered the IE17. This is in agreement with the recent findings of Calderoni et al. (2019), who associate the recent seismicity of Ischia to a fault-valve type mechanism consistent with the periodic pressurization of the hydrothermal reservoir induced by self-sealing processes. The pressurization 
cycles are then followed by depressurization episodes associated with ruptures and reactivation of the faults that generates seismicity. A possible indication of the pressure buildup in the shallow hydrothermal system could be represented by higher energetic values in RMS observed in 2017. The hydrothermal flux increase would also have enhanced the 3$4 \mathrm{~Hz}$ signal (activating the second mode in agreement with the organ pipe like model), well extracted by ICA from the earthquakes, otherwise weaker in the noise. The observation of two main components in the seismic signals also matches the results of recent laboratory experiments carried out by Fazio et al. (2017), who analyzed the waveforms produced during the decompression of two-phase fluids under controlled temperature and confining pressure conditions. These authors notice that the fluid-driven signals associated to the liquid-gas mixtures (e.g. water/steam bubbly fluid) are generally characterized by a two-peak spectrum.

In line with the previous results, we attribute the extracted components in both the noise and the earthquakes to a common phenomenon of fluid-solid interaction in the hydrothermal system of Ischia Island. This information can shed light on both the source processes and/or the medium properties at different time scale (i.e. the one generating "noise" and the transients), as well as on the link between the two.

Data availability. Data are available on request from the authors.

Author contributions. PC, SP, EDL, SDM, MF conceived the original idea of the present research. PC, SP, EDL, MF elaborated and validated the data. All the authors contributed to the modeling and in writing the manuscript.

Competing interests. The authors declare that they have no conflict of interest.

Special issue statement. This article is part of the special issue "Understanding volcanic processes through geophysical and volcanological data investigations: some case studies from Italian sites (EGU2019 GMPV5.11 session, COV10 S01.11session)". It is not associated with a conference.

Acknowledgements. The authors wish to thank Teresa Caputo and an anonymous referees for their useful comments that contributed to improve this manuscript.

Review statement. This paper was edited by Danilo Galluzzo and reviewed by Teresa Caputo and one anonymous referee.

\section{References}

Aki, K., Fehler, M., and Das, S.: Source mechanism of volcanic tremor: fluid-driven crack models and their application to the 1963 Kilauea eruption, J. Volcanol. Geoth. Res., 2, 259-287, https://doi.org/10.1016/0377-0273(77)90003-8, 1977.

Bottiglieri, M., Falanga, M., Tammaro, U., Obrizzo, F., De Martino, P., Godano, C., and Pingue, F.: Independent component analysis as a tool for ground deformation analysis, Geophys. J. Int., 168, 1305-1310, https://doi.org/10.1111/j.1365-246X.2006.03264.x, 2007.

Braun, T., Famiani, D., and Cesca, S.: Seismological Constraints on the Source Mechanism of the Damaging Seismic Event of 21 August 2017 on Ischia Island (Southern Italy), Seism, Res, Lett., 89, 1741-1749, https://doi.org/10.1785/0220170274, 2018.

Calderoni, G., Di Giovambattista, R., Pezzo, G., Albano, M., Atzori, S., Tolomei, C., and Ventura, G.: Seismic and Geodetic Evidences of a Hydrothermal Source in the $M_{\mathrm{d}} 4.0$, 2017, Ischia Earthquake (Italy), J. Geophys. Res.-Sol. Ea., 124, 5014-5029, https://doi.org/10.1029/2018JB016431, 2019.

Caliro, S., Panichi, C., and Stanzione, D.: Variation in the total dissolved carbon isotope composition of thermal waters of the Island of Ischia (Italy) and its implications for volcanic surveillance, J. Volcanol. Geotherm. Res., 90, 219-240, https://doi.org/10.1016/S0377-0273(99)00027-X, 1999.

Capuano, P., De Lauro, E., De Martino, S., and Falanga, M.: Detailed investigation of long-period activity at Campi Flegrei by convolutive independent component analysis, Phys. Earth Planet. Int., 253, 48-57, https://doi.org/10.1016/j.pepi.2016.02.003, 2016.

Capuano, P., De Lauro, E., De Martino, S., Falanga, M., and Petrosino, S.: Convolutive independent component analysis for processing massive datasets: a case study at Campi Flegrei (Italy), Nat. Hazards, 86, 417-429, https://doi.org/10.1007/s11069-0162545-0, 2017.

Carlino, S., Somma, R., Troiano, A., Di Giuseppe, M. G., Troise, C., and De Natale, G.: The geothermal system of Ischia Island (southern Italy): Critical review and sustainability analysis of geothermal resource for electricity generation, Renewable Energy, 62, 177-196, https://doi.org/10.1016/j.renene.2013.06.052, 2014.

Chiodini, G., Giudicepietro, F., Vandemeulebrouck, J., Aiuppa, A., Caliro, S., De Cesare, W., Tamburello, V., Avino, R., Orazi, M., and D'Auria, L.: Fumarolic tremor and geochemical signals during a volcanic unrest, Geology, 45, 1131-1134, https://doi.org/10.1130/G39447.1, 2017.

Chouet, B. A. and Matoza, R. S.: A multi-decadal view of seismic methods for detecting precursors of magma movement and eruption, J. Volcanol. Geotherm. Res., 252, 108-175, https://doi.org/10.1016/j.jvolgeores.2012.11.013, 2013.

Ciaramella, A., De Lauro, E., De Martino, S., Falanga, M., and Tagliaferri, R.: ICA based identification of dynamical systems generating synthetic and real world time series, Soft Comput., 10, 587-606, 2006.

Cusano, P., Petrosino, S., De Lauro, E., and Falanga, M.: The whisper of the hydrothermal seismic noise at Ischia Island, J. Volcanol. Geotherm. Res., 389, 106693, https://doi.org/10.1016/j.jvolgeores.2019.106693, 2020.

D’Auria, L., Giudicepietro, F., Tramelli, A., Ricciolino, P., Lo Bascio, D., Orazi, M., Martini, M., Peluso, R., Scarpato, G., and Es- 
posito, A.: The Seismicity of Ischia Island, Seis. Res Lett., 89, 1750-1760, https://doi.org/10.1785/0220180084, 2018.

De Lauro, E., Falanga, M., and Petrosino, S.: Study on the longperiod source mechanism at Campi Flegrei (Italy) by a multiparametric analysis, Phys. Earth Planet. Int., 206-207, 16-30, https://doi.org/10.1016/j.pepi.2012.06.006, 2012.

De Lauro, E., De Martino, S., Falanga, M., and Petrosino, S.: Synchronization between tides and sustained oscillations of the hydrothermal system of Campi Flegrei (Italy), Geochem. Geophys. Geosyst., 14, 2628-2637, https://doi.org/10.1002/ggge.20149, 2013.

De Lauro, E., De Martino, S., Falanga, M., and Petrosino, S.: Fast wavefield decomposition of volcano-tectonic earthquakes into polarized $\mathrm{P}$ and $\mathrm{S}$ waves by Independent Component Analysis, Tectonophysics, 690, 355-361, https://doi.org/10.1016/j.tecto.2016.10.005, 2016.

De Lauro, E., Petrosino, S., Ricco, C., Aquino, I., and Falanga, M.: Medium and long period ground oscillatory pattern inferred by borehole tiltmetric data: new perspectives for the Campi Flegrei caldera crustal dynamics, Earth Planet. Sc. Lett., 504, 21-29, https://doi.org/10.1016/j.epsl.2018.09.039, 2018.

De Novellis, V., Carlino, S., Castaldo, R., Tramelli, A., De Luca, C., Pino, N. A., Pepe,S., Convertito, V., Zinno, I., De Martino, P., Bonano, M., Giudicepietro, F., Casu, F., Macedonio, G., Manunta, M., Cardaci, C., Manzo, M., Di Bucci, D., Solaro, G., Zeni, G., Lanari, R., Bianco, F., and Tizzani, P.: The 21 August 2017 Ischia (Italy) earthquake source model inferred from seismological, GPS, and DInSAR measurements, Geophys. Res. Lett., 45, 2193-2202, https://doi.org/10.1002/2017GL076336, 2018.

de Vita, S., Sansivero, F., Orsi, G., Marotta, E., and Piochi, M.: Volcanological and structural evolution of the Ischia resurgent caldera (Italy) over the past $10 \mathrm{ky}$, Geol. Soc. Am. Spec. Pap., 464, 193-239, 2010.

Devoti, R., De Martino, P., Pietrantonio, G., and Dolce, M.: Coseismic displacements on Ischia Island, real-time GPS positioning constraints on earthquake source location, Ann. Geophys., 61, SE337, https://doi.org/10.4401/ag-7656, 2018.

Di Giuseppe, M. G., Troiano, A., and Carlino, S.: Magnetotelluric imaging of the resurgent caldera on the island of Ischia (southern Italy): inferences for its structure and activity, Bull. Volcanol., 79, 85, https://doi.org/10.1007/s00445-017-1170-4, 2017.

Di Napoli, R., Aiuppa, A., Bellomo, S., Brusca, L., D’Alessandro, W., Gagliano Candela, E., Longo, M., Pecoraino, G., and Valenza, M.: A model for Ischia hydrothermal system: evidences from the chemistry of thermal groundwaters, J. Volcanol. Geotherm. Res., 186, 133-159, https://doi.org/10.1016/j.jvolgeores.2009.06.005, 2009.

Di Napoli, R., Federico, C., Aiuppa, A., D’Antonio, M., and Valenza, M.: Quantitative models of hydrothermal fluid-mineral reaction: The Ischia case, Geochim. Cosmochim. Ac., 105, 108129, https://doi.org/10.1016/j.gca.2012.11.039, 2013.

Falanga, M., De Lauro, E., Petrosino, S., and De Martino, S.: Interaction between seismicity and deformation on different time scales in volcanic areas: Campi Flegrei and Stromboli, Adv. Geosci., 52, 1-8, https://doi.org/10.5194/adgeo-52-1-2019, 2019.

Fazio, M., Benson, P. M., and Vinciguerra, S.: On the generation mechanisms of fluid-driven seismic signals related to volcano-tectonics, Geophys. Res. Lett., 44, 734-742, https://doi.org/10.1002/2016GL070919, 2017.

Galluzzo, D., Nardone, L., Carandente A., Buonacunto, C., Scarpato, G., Marotta, E., Milano, G., Govoni, A., and Moretti, M.,: Le attività del gruppo operativo SISMIKO in occasione del terremoto di Ischia MW 3.9 (MD 4.0) del 21 Agosto 2017, Quad. Geofis., 154, 1-28, 2019.

Hyvärinen, A. Karhunen, J., and Oja, E.: Independent Component Analysis, John Wiley \& Sons, New York, 2001.

Kawakatsu, H. and Yamamoto, M.: Volcano Seismology, in: Treatise on Geophysics, edited by: Schubert, G., Elsevier, Oxford, 4, 389-420, 2007.

Madonia, P., Federico, C., Cusano, P., Petrosino, S., Aiuppa, A., and Gurrieri, S.: Crustal dynamics of Mount Vesuvius from 1998 to 2005: Effects on seismicity and fluid circulation, J. Geophys. Res., 113, B05206, https://doi.org/10.1029/2007JB005210, 2008.

McNutt, S. R.: Volcanic seismology, Ann. Rev. Earth Planet. Sci., 32, 461-491, https://doi.org/10.1146/annurev.earth.33.092203.122459, 2005.

Montalbetti, J. F. and Kanasewich, E. R.: Enhancement of teleseismic body phases with a polarization filter, Geophys. J. Int., 21, 119-129, https://doi.org/10.1111/j.1365-246X.1970.tb01771.x, 1970.

Moretti, M., Pondrelli, S., Margheriti, L., Abruzzese, L., Anselmi, M., Arroucau, P., Baccheschi, P., Baptie, B., Bonadio, R., Bono, A., Bucci, A., Buttinelli, M., Capello, M., Cardinale, V., Castagnozzi, A., Cattaneo, M., Cecere, G., Chiarabba, C., Chiaraluce, L., Battista Cimini, G., Cogliano, R., Colasanti, G., Colasanti, M., Criscuoli, F., D'Alema, E., D’Alessandro, A., D’Ambrosio, C., Danecek, P., De Caro, M., De Gori, P., Delladio, A., De Luca, G., De Luca, G., Demartin, M., Di Nezza, M., Di Stefano, R., Falco, L., Fares, M., Frapiccini, M., Frepoli, A., Galluzzo, D., Giandomenico, E., Giovani, L., Giunchi, C., Govoni, A., Hawthorn, D., Ladina, C., Lauciani, V., Lindsay, A., Mancini, S., Mandiello, A. G., Marzorati, S., Massa, M., Memmolo, A., Migliari, F., Minichiello, F., Monachesi, G., Montuori, C., Moschillo, R., Murphy, S., Pagliuca, N. M., Pastori, M., Piccinini, D., Piccolini, U., Pintore, S., Poggiali, G., Rao, S., Saccorotti, G., Segou, M., Serratore, A., Silvestri, M., Silvestri, S., Vallocchia, M., Valoroso, L., Zuccarello, L., Michelini, A., and Mazza, S.: SISMIKO: emergency network deployment and data sharing for the 2016 central Italy seismic sequence, Ann. Geophys., 59, 1-8, https://doi.org/10.4401/ag-7212, 2016.

Nappi, R., Alessio, G., Gaudiosi, G., Nave, R., Marotta, E., Siniscalchi, V., Civico, R., Pizzimenti, L., Peluso, R., Belviso, P., and Porfido, S.: The 21 August $2017 M_{\mathrm{d}} 4.0$ Casamicciola earthquake: First evidence of coseismic normal surface faulting at the Ischia volcanic island, Seism. Res. Lett., 89, 1323-1334, https://doi.org/10.1785/0220180063, 2018.

Orsi, G., Gallo, G., and Zanchi, A.: Simple-shearing block resurgence in caldera depression. A model from Pantelleria and Ischia, J. Volcanol. Geotherm. Res., 47, 1-11, https://doi.org/10.1016/0377-0273(91)90097-J, 1991.

Palo, M. and Cusano, P.: Wavefield decomposition and phase space dynamics of the seismic noise at Volcàn de Colima, Mexico: evidence of a two-state source process, Nonlin. Processes Geophys., 20, 71-84, https://doi.org/10.5194/npg-20-71-2013, 2013. 
Petrosino, S., Cusano, P., and Madonia, P.: Tidal and hydrological periodicities of seismicity reveal new risk scenarios at Campi Flegrei caldera, Sci. Rep.-UK, 8, 13808, https://doi.org/10.1038/s41598-018-31760-4, 2018.

Petrosino, S., Ricco, C., De Lauro, E., Aquino, I., and Falanga, M.: Time evolution of medium and long-period ground tilting at Campi Flegrei caldera, Adv. Geosci., 52, 9-17, https://doi.org/10.5194/adgeo-52-9-2020, 2020.

Piochi, M., Mormone, A., and Balassone, G.: Hydrothermal alteration environments and recent dynamics of the Ischia volcanic island (southern Italy): Insights from repeated field, mineralogical and geochemical surveys before and after the 2017 Casamicciola earthquake, J. Volcanol. Geotherm. Res., 376, 104-124, https://doi.org/10.1016/j.jvolgeores.2019.03.018, 2019.
Ricco, C., Petrosino, S., Aquino, I., Del Gaudio, C., and Falanga, M.: Some Investigations on a Possible Relationship between Ground Deformation and Seismic Activity at Campi Flegrei and Ischia Volcanic Areas (Southern Italy), Geosciences, 9, 222, https://doi.org/10.3390/geosciences9050222, 2019.

Rovida, A., Locati, M., Camassi, R., Lolli, B., and Gasperini, P.: Italian Parametric Earthquake Catalogue (CPTI15), version 2.0, Istituto Nazionale di Geofisica e Vulcanologia (INGV), Rome, Italy, https://doi.org/10.13127/CPTI/CPTI15.2, 2019. 